\title{
Wenn die Tarifautonomie fällt, kommt das Globalbudget
}

\author{
Jürg Schlup \\ Dr. med., Präsident der FMH
}

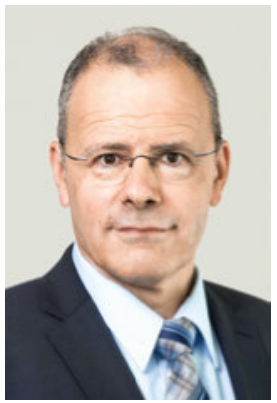

Mit den Beschlüssen der FMH-Delegiertenversammlung vom Januar (siehe U. Stoffel, SÄZ 6/2017, S. 177) werden ein gemeinsam nachgebesserter und mehrheitsfähiger Revisionsvorschlag - und damit auch Verhandlungen mit den Tarifpartnern - wieder absehbar. Ein realistischer Zeitplan für das Einreichen einer genehmigungsfähigen Tarifstruktur bis Mitte 2018 liegt vor.

Auch wenn wir in diesem hochkomplexen Revisionsprojekt unser Bestes geben, bleiben wir darauf angewiesen, dass die Politik die Tarifautonomie nicht endgültig zu Grabe trägt, bevor wir unseren Vorschlag einreichen können. Denn immer häufiger werden Stimmen laut, die in einer umfassenden Tarifkompetenz des Bundes die Lösung zur Steuerung der über TARMED verrechneten Krankheitsleistungen sehen. Das, obschon diese Leistungen heute gerade einmal einen Anteil von rund 15\% an den gesamten Gesundheitskosten haben.

Wie man hier sparen möchte, teilte das Departement des Innern im September 2016 mit: Man wolle «das zu starke Mengenwachstum in den Griff» bekommen [1] und prüfe dafür auch die Steuerung über Budgets. Zudem beauftragte die Finanzdelegation der eidgenössischen Räte den Bundesrat, "Gesetzesentwürfe vorzubereiten, damit er rasch und konkret handeln kann» [2].

\section{An einer kompromisslosen sektoriellen Kostenneutralität kann unsere Versorgungs- sicherheit scheitern.}

Die Gesundheitskommission des Nationalrats legte Anfang Februar 2017 nach und fordert nun «einen Mechanismus zur Steuerung der Kosten und der Leistungen». Budgetierung und Mengenbegrenzungen - und somit letztlich Rationierung - sind in der ambulanten Versorgung damit kein Tabu mehr! Stehen wir vor einem Paradigmenwechsel unserer ambulanten Versorgung? An der vom Bund kompromisslos diktierten Kostenneutralität für den ambulanten OKP-Bereich könnten nicht nur die ambulant tätigen Ärzte und deren Tarifautonomie scheitern, sondern auch unsere Versorgungssicherheit. Denn eine zunehmend älter wer-

dende Bevölkerung kann nicht mit stetig besseren ambulanten Behandlungsmöglichkeiten zu gleichen Kosten versorgt werden. Diesen schwarzen Rationierungs-Peter versucht eine Mehrheit der Gesundheitskommission nun offenbar den Leistungserbringern zuzuschieben: Wenn das Budget zu Ende geht, sollen wir künftig implizit Leistungen vorenthalten. Stattdessen brauchen wir intelligente Lösungen, wie gute ambulante Versorgung möglichst kostengünstig erbracht werden kann. Wer über die Prämien, die 40\% der Gesundheitskosten abbilden, hinausschaut,

\section{Wir brauchen intelligente Lösungen,} wie gute ambulante Versorgung möglichst kostengünstig erbracht werden kann.

erkennt, dass der wachsende ambulante Versorgungsbereich nicht das Problem, sondern Teil der Lösung ist, denn durch ambulante Behandlungen sparen wir häufig deutlich teurere stationäre Behandlungen ein. Durch die ungleiche Finanzierung von stationären und ambulanten Leistungen führen solche Kosteneinsparungen aber zu Prämiensteigerungen - und werden darum häufig nicht realisiert. Wer Kosten sparen möchte, muss die unterschiedliche Finanzierung stationärer und ambulanter Leistungen vereinheitlichen. Wer aber - wie die Mehrheit der Gesundheitskommission des Nationalrats - in der ambulanten Medizin auf «einen Mechanismus zur Steuerung der Kosten und Leistungen" [3] setzt, spart nur Leistungen ein - auf Kosten der Patienten.

Bevor der Gesetzgeber mit gedeckelten Budgets die Versorgungssicherheit gefährdet, müsste er das Einsparpotential einer einheitlichen Finanzierung ambulanter und stationärer Leistungen realisieren - und sollte die Tarifpartner ihre Revisionsarbeit machen lassen.

\section{Literatur}

1 Medienmitteilung des EDI vom 2.9.2016: Mengenwachstum im Gesundheitswesen eindämmen.

2 Ständeratsprotokoll vom 21.9.2016: Ständerätin A. Fetz, Präsidentin der Finanzdelegation.

3 Medienmitteilung des Sekretariats der Kommissionen für soziale Sicherheit und Gesundheit vom 3.2.2017 zur ambulanten Medizin. 